\title{
Perencanaan Co-Working Space dalam Peningkatan SDM di Kabupaten Lumajang
}

\author{
Riza Bahtiar Sulistyan*1, Ninik Lukiana², M. Ato'illah ${ }^{3}$ \\ 1,2,3Program Studi Manajemen, Institut Teknologi dan Bisnis Widya Gama Lumajang, Indonesia \\ *e-mail: $\underline{\text { rizabahtiars@gmail.com }}$, ibundaninik@gmail.com $^{2}$, atokwiga73@gmail.com $^{3}$
}

\begin{abstract}
Abstrak
Konsep Co-Working Space mulai banyak dikembangkan di beberapa daerah di Indonesia. Namun mash perlu adanya perencanaan yang matang agar dapat meminimalisisr tingkat kesalahan dan dapat sesuai dengan rencana. Lokasi Co-Working Space di Kabupaten Lumajang yang masih dalam tahap perencanaan perlu dilakukan pendampingan agar sesuai dengan tujuan adanya Co-Working cpace. Metode yang dilakukan berupa perencanaa, pelaksanaan, dan evaluasi Hasil menunjukkan bahwa pengelola CoWorking Space di Perpustakaan Lumajang menunjukkan peningkatan kompetensi dalam perencanaan pembuatan Co-Working Space yang efektif. Peningkatan ditunjukkan dari pengetahuan mengenai perencanaan konsep dan sistem yang matang. Ditunjang dengan gambaran rencana dan penataan tempat. Peningkatan pemahaman yang lebih mendalam dalam perencanaan ditunjukkan dari hasil yang maksimal. Penting untuk dilakukan pendampingan sampai dengan Co-Working Space dapat berjalan.
\end{abstract}

Kata kunci: Co-Working Space, Efektivitas, Pendampingan, Perencanaan

\section{Abstract}

The concept of Co-Working Space has begun to be developed in several regions in Indonesia. However, there is still a need for careful planning so that it can minimize the error rate and can be in accordance with the plan. The location of a Co-Working Space in Lumajang Regency which is still in the planning stage needs to be provided with assistance so that it is in accordance with the purpose of having a Co-Working cpace. The methods used are planning, implementation, and evaluation. The results show that the manager of the Co-Working Space at the Lumajang Library shows an increase in competence in planning the creation of an effective Co-Working Space. Improvement is shown from knowledge of mature concept planning and systems. Supported by an overview of the plan and arrangement of the place. Improved deeper understanding in planning is shown from the maximum results. It is important to provide assistance until the Co-Working Space can run.

Keywords: Co-Working Space, Effectiveness, Mentoring, Planning

\section{PENDAHULUAN}

Di era saat ini, penggunaan seluler telah merubah sikap untuk bekerja kapanpun dan dimanapun. Penggunaan teknologi membuat para pekerja pemula maupun tetap bisa bekerja dimana saja untuk mencari ruang kerja bersama yang luas jaringan dan kolaborasi. Namun, disisi lain seseorang juga membutuhkan lingkungan kerja yang mendukung (Weijs-Perrée, van de Koevering, Appel-Meulenbroek, \& Arentze, 2019). Pekerja yang didukung dengan ruang kerja yang nyaman dan mendukung harapannya adalah dapat meningkatkan produktivitas kerjanya. Oleh karena itu, organisasi perlu membangun lingkungan kerja internal yang nyaman dengan berbagai fasilitas dimana dapat meningkatkan kreativitas pekerjaan (Fuzi, Clifton, \& Loudon, 2014). Lingkungan kerja seperti ini biasa disebut sebagai Co-Working Space. Konsep CoWorking Space dapat diidentifikasikan dalam kantor publik, tempat ketiga dalam pekerjaan, hubungan kolaborasi, hotel Co-Working, inkubator, dan studio bersama. Kategori ini didasarkan atas model bisnis (untuk profit atau non profit) dan tingkat akses pengguna (public, semi privat, dan privat) (Kojo \& Nenonen, 2016).

Seperti di Pekanbaru, Co-Working ini merupakan peluang bisnis yang mampu mendorong industri di berbagai bidang (Kurnia, Putri, Syafira, \& Suci, 2021). Terlebih pada konsep kafe, bisnis Co-Working Space konsep cafe ini lebih cepat meningkat karena menjadi tempat rutinitas para siswa, pekerja freelancer, influencer dalam aktivitas sehari-hari karena 
terfasilitasi makanan dan minuman yang dijual, serta tempat yang nyaman (Fauzia, Suharno, \& Guritno, 2020). Co-Working Space masih diterapkan di kota-kota besar, seperti Jakarta (Lestari, 2019; Simarmata, Gunanta, \& Fatimah, 2020), Bandung (Surbakti \& Danil, 2020), Surabaya (Tsamara \& Nugraha, 2021), Malang (Asyhar, 2018), dan Yogyakarta (Andriani, Musyawaroh, \& Nugroho, 2020; Darusuprapta \& Dirgantara, 2019). Co-Working Space juga akan dikembangkan di Kabupaten Lumajang yang digunakan untuk meningkatkan kualitas Sumber Daya Manusia. Terutama pada suasana kerja yang berbeda, kemauan dalam mengolah pikiran, memperbarui dan menambah wawasan-wawasan. Sehingga terbentuk pola pikir baru masyarakat Lumajang yang memadai. Pada survei awal, Co-Working Space di Kota Lumajang masih dalam tahap perencanaan dan belum dilaksanakan. Sehingga Lumajang menjadi tempat pilihan penelitian ini. Penentuan Lokasi yang strategis, sistem dan konsep menjadi hal yang harus di pikirkan dan dipersiapkan dengan matang.

SDM menjadi unsur utama dalam pengembangan, terutama penguasaan teknologi yang semakin meningkat kedepannya (Sebastian, 2015). Sehingga, dibutuhkan adanya aktivitas manajemen melalui pengaruh lingkungan kerja dan pengembangan sumber daya manusia yang menunjang kinerja untuk mencapai target yang maksimal. Hal tersebut bisa dimulai dengan adanya ruang kerja bersama atau Co-Working Space sebagai inovasi pemecahan masalah SDM di kota untuk menciptakan ekosistem yang memadai dan mampu bersaing tingkat global guna meningkatkan sumber daya manusia (Pratiwi \& Kurniawan, 2021). Lingkungan kerja yang nyaman tentu akan dapat meningkatkan kinerja (Sulistyan, 2017).

Co-Working Space yang masih dalam konsep baru di Kabupaten Lumajang masih perlu adanya pendampingan perencanaan. Pentingnya perencanaan akan lebih mematangkan proses pelaksanaan dan menimimalisir tingkat kesalahan (Sulistyan \& Paramita, 2021). Pendampingan dapan dilakukan dengan beberapa cara misalnya dengan perencanaan arsitektur (Andriani et al., 2020), pendampingan perencanaan kawasan (Mutiari, Muhammad, \& Raditya S, 2020), dan pendampingan perencanaan dengan survei langsung (Sulistyan \& Paramita, 2021).

\section{METODE}

Metode yang digunakan berupa tahap persiapan, pelaksanaan, dan evaluasi (Sulistyan, Setyobakti, \& Darmawan, 2019). Ketiga tahap akan dilakukan dengan detail kegiatan sebagai berikut: 1) Tahap persiapan persiapan dilakukan dengan melakukan identifikasi permasalahan lebih mendalam pada rencana pembuatan Co-Working Space model di Perpustakaan Kabupaten Lumajang, 2) Tahap pelaksanaan dilakukan setelah identifikasi permasalahan benar-benar mendapatkan solusi yang tepat. Tahap ini akan dilakukan pendampingan dalam perencanaan pembuatan Co-Working Space model yang efektif bagi masyarakat Lumajang. Pelaksanaan ini diawali dengan memberikan pemahaman yang tepat dalam merencanakan penataan tempat, fasilitas, suasana yang dibangun agar mencapai tujuan kenyamanan masyarakat untuk datang ke Co-Working Space di Perpustakaan Lumajang, dan 3) Tahap evaluasi digunakan untuk menilai tingkat keberhasilan dari perencanaan pelaksanaan pembuatan Co-Working Space model di Perpustakaan Kabupaten Lumajang.

\section{HASIL DAN PEMBAHASAN}

Kegiatan penelitian ini dilaksanakan sesuai dengan tahapan yang sudah direncanakan, mulai dari tahap persiapan, tahap pelaksanaan, dan tahap evaluasi. Hasil pelaksanaan kegiatan dijabarkan sebagai berikut:

a. Tahap Persiapan

Tahap persiapan dilaksanakan dengan melakukan identifikasi permasalahan yang terjadi pada rencana pembuatan Co-Working Space di Peepustakaan Lumajang. Permasalahan yang ditemukan berupa belum menemukan model yang efektif dan dibutuhkan oleh masyarakat Lumajang. Pematangan konsep dan pematangan sistem yang akan diterapkan nanti akan bertujuan baik untuk kenyamanan dan kebutuhan masyarakat Lumajang. Kemudian 
merencanakan untuk survei ke beberapa lokasi Co-Working Space di luar kota sebagai role model dan pembanding.

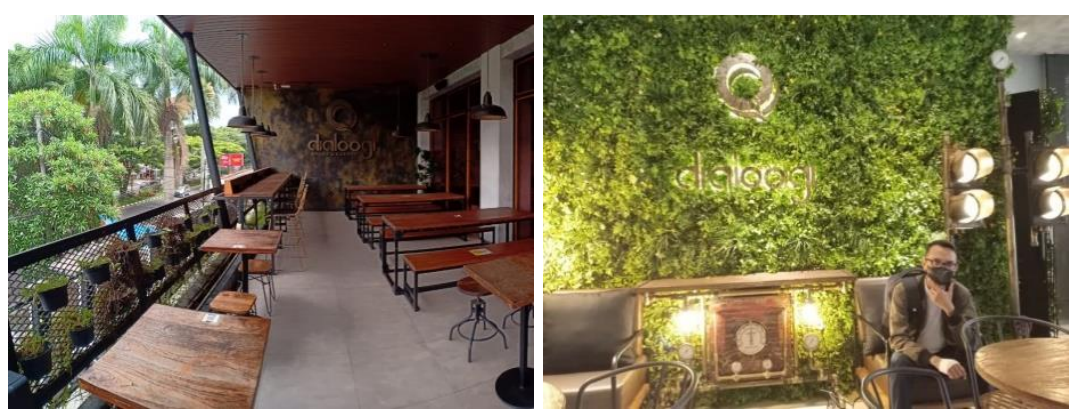

Gambar 1. Survei Co-Working Space sebagai Pembanding

b. Tahap Pelaksanaan

Tahap pelaksanaan dimulai pada pembuatan rencana, kemudian survei ke beberapa lokasi Co-Working Space yang ada di luar kota. Survei ini akan mempermudah mendapatkan inovasi dan konsep baru yang bisa menjadi pembanding dan diterapkan di Perpustakaan Lumajang. Survei dilaksanakan untuk merasakan suasana secara langsung sebagai pengunjung di tempat Co-Working Space A, dengan tempat di Co-Working Space B, C, dan seterusnya dengan pelayanan, fasilitas dan suasana yang berbeda. Kemudian mewawancarai beberapa pelayan dan pengunjung untuk mengetahui kepuasan seperti apa yang mereka dapat dan bagaimana pelayanan yang disenangi oleh pengunjung.
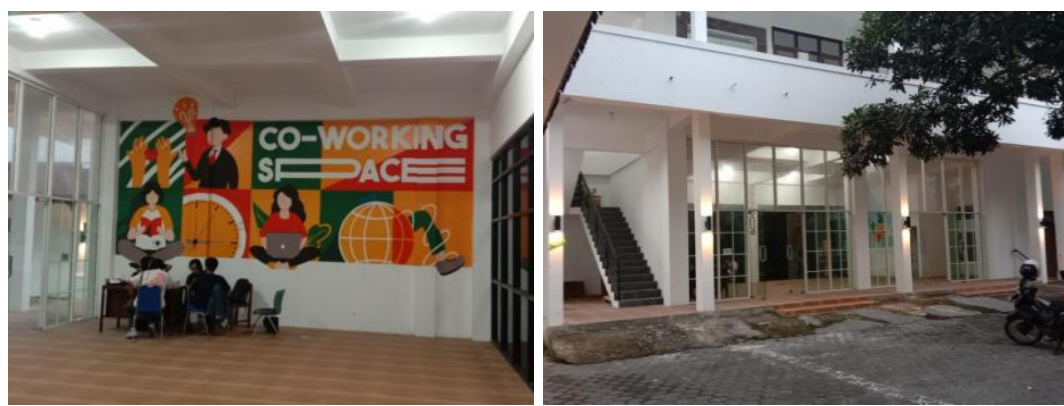

Gambar 2. Rencana Co-Working Space di Lumajang

c. Tahap Evaluasi

Evaluasi dilakukan untuk menilai tingkat penyesuaian dan kecocokan Co-Working Space model yang akan diterapkan di perpustakaan Lumajang. Cukup atau tidaknya lahan yang ada. Penyesuaian dan penentuan tempat yang pas dan strategis bagi masyarakat Lumajang. Dan kemudahan akses untuk dekat dengan lingkungan Kota dan mudah dijangkau. Dalam evaluasi ini dapat ditentukan bagaimana konsep dan sistem yang tepat dan efektif diterapkan di Perpustakaan Lumajang.

Perpustakaan di Lumajang sangat strategis bila menjadi lokasi pelaksanaan Co-Working Space model untuk wadah ruang kerja bersama masyarakat Lumajang dalam berkarya, mengolah pikiran, menambah ilmu, berbagi, dan saling tumbuh bersama dalam meningkatkan kualitas SDM di Lumajang. Lokasi Perpustakaan berada di tengah kota Lumajang dan dekat dengan Alun-alun Kota Lumajang yang merupakan pusat keramaian dan tempat berkumpul anak-anak muda. Adanya Co-Working Space ditempat yang strategis ini bisa menjadikan tongkrongan-tongkrongan anak muda di alun-alun kota Lumajang menjadi lebih bermanfaat dan terkonsep untuk lebih produktif kedepannya. Selain itu, perpustakaan Lumajang juga menyediakan buku-buku yang telah di upgrade dan bermanfaat kedepannya, sehingga masyarakat bisa meminjam buku di perpustakaan dan bisa membacanya dengan suasana yang berbeda dan baru di tempat Co-Working Space. 
Pengelolaan dengan sistem yang mempermudah pengunjung akan menjadi hal yang menarik perhatian dan semangat mereka untuk datang ke Co-Working Space di Perpustakaan Lumajang. Fasilitas yang lengkap seperti penyewaan Laptop, Wi-fi, adanya stop kontak di setiap bangku, ruangan nyaman ber-AC dan outdoor khusus perokok akan mendapat kepuasan tersendiri bagi pengunjung.

Tidak hanya itu, konsep ruangan yang dipilih juga akan mempengaruhi suasana CoWorking Space yang menentukan kenyamanan pengunjung. Konsep bisa diambil dengan bermacam-macam gaya. Adapun beberapa konsep seperti vintage, aesthethic (cafe), kemudian tema classic seperti tempat-tempat pusat belajar di Luar Negeri, atau colourfull yang dapat meningkatkan semangat berpikir anak-anak muda dan merefresh otak kalangan pekerja dewasa yang bosan dengan situasi kantor yang tidak berubah. Hal ini sangat menentukan ketertarikan, dan kenyamanan dari pengunjung. Keunikan konsep yang tidak ditemui di Lokasi lain akan membuat pengunjung tidak hanya satu kali atau dua kali datang, tapi bisa menjadi rutinitas mereka untuk datang ke Co-Working Space di Perpustakaan Lumajang. Dengan hal ini, semangat mereka untuk bekerja, belajar, dan berbagi ilmu semakin bertambah. Selain itu mereka juga dapat menambah jaringan, sehingga mampu membentuk suatu projek baru dengan tujuan konsistensi berkarya dan meningkatkan produktivitas.

Penentuan harga dari makanan atau minuman yang dijual juga harus diperhatikan. Sebab apabila pengunjung lebih banya dari kalangan siswa SMP, SMA, SMK atau Mahasiswa, maka harga makanan dan minuman yang dijual harus bisa dijangkau oleh mereka. Harga yang murah dan porsi yang cukup harus dipertimbangkan dengan matang. Sehingga pengunjung bisa datang berkali-kali ke Lokasi Co-Working Space yang ada di Perpustakaan Lumajang.

\section{KESIMPULAN}

Berdasarkan hasil kegiatan pendampingan perencanaan diperoleh kesimpulan bahwa mitra Pengelola Co-Working Space di Perpustakaan Lumajang menunjukkan peningkatan kompetensi dalam perencanaan pembuatan Co-Working Space yang efektif. Peningkatan ditunjukkan dari pengetahuan mengenai perencanaan konsep dan sistem yang matang. Ditunjang dengan gambaran rencana dan penataan tempat. Peningkatan pemahaman yang lebih mendalam dalam perencanaan ditunjukkan dari hasil yang maksimal.

\section{DAFTAR PUSTAKA}

Andriani, R. E., Musyawaroh, \& Nugroho, P. S. (2020). Konsep Creative Coworking Space pada Pusat Inkubasi Startup di Yogyakarta. Senthong, 3(1), 146- 155.

Asyhar, K. (2018). Understanding Coworking Space as a New Concept of Workplace (A Study on Coworking Spaces in Malang City). Jurnal Ilmiah Mahasiswa Fakultas Ekonomi dan Bisnis, 7(2), 1-16.

Darusuprapta, F., \& Dirgantara, I. M. B. (2019). Studi tentang Faktor-Faktor Atmosfer Lingkungan Terhadap Keterikatan Pelanggan pada Coworking Space di Yogyakarta. Diponegoro Journal of Management, 8(3), 113-127.

Fauzia, A., Suharno, \& Guritno, A. D. (2020). Consumer needs and consumer satisfaction in the creation of Co-Working Space café business concept. IOP Conference Series: Earth and Environmental Science, 425(1), 012032. doi: 10.1088/1755-1315/425/1/012032

Fuzi, A., Clifton, N., \& Loudon, G. (2014). New in-house organizational spaces that support creativity and innovation: the Co-Working Space. Paper presented at the R \& D Management Conference.

Kojo, I., \& Nenonen, S. (2016). Typologies for Co-Working Spaces in Finland - what and how? Facilities, 34(5/6), 302-313. doi: 10.1108/f-08-2014-0066 
Kurnia, W. R., Putri, N. E., Syafira, M. N., \& Suci, R. G. (2021). Analysis of Opportunities and Challenges of Co-Working Space Industry Case Study: Pekanbaru Co-Working Space Meetup. Research In Accounting Journal, 1(3), 370-375.

Lestari, E. D. (2019). The Co-Working Space as a Business with Higher Purposes (Case Study of Co-Working Spaces in Jakarta)tari_2019_E_R.pdf>. International Journal of Innovation, Creativity and Change, 5(6), 803-812.

Mutiari, D., Muhammad, J. M., \& Raditya S, R. (2020). Pendampingan Perencanaan Kawasan Desa Wisata Jayan Senting Sambi Boyolali. Jurnal Pengabdian Masyarakat Teknoyasa, 1(2), 27-35. doi: 10.23917/abditeknoyasa.v1i2.188

Pratiwi, R., \& Kurniawan, B. (2021). Implementasi Program Cak E-MUS (Cangkrukan Entrepreneur Muda Surabaya) dalam Mengembangkan Dunia Bisnis yang Memberdayakan Anak Muda Surabaya. Publika, 9(3), 294-306.

Sebastian, E. (2015). Peningkatan Peranan SDM Pertahanan Nasional Guna Menghadapi Perang Generasi Keempat. Jurnal Pertahanan, 5(1), 109-128. doi: 10.33172/jpbh.v5i1.351

Simarmata, C., Gunanta, S., \& Fatimah, T. (2020). Co-Working Space with Biophilic Design Approach in Lot.6 SCBD, South Jakarta. IOP Conference Series: Materials Science and Engineering, 1007(1), 012081. doi: 10.1088/1757-899x/1007/1/012081

Sulistyan, R. B. (2017). Contribution Of Leadership And Environmental Work In Improving Employee Motivation. Jurnal Ilmu Manajemen Advantage, 1(2), 166-177.

Sulistyan, R. B., \& Paramita, R. W. D. (2021). Business Location Planning Assistance: Preservation of Traditional Culture of Kampoeng Batara Banyuwangi. Empowerment Society, 4(1), 17-21. doi: 10.30741/eps.v4i1.634

Sulistyan, R. B., Setyobakti, M. H., \& Darmawan, K. (2019). Strategi Pemberdayaan Masyarakat melalui Program Pembentukan Destinasi Wisata dan Usaha Kecil. Empowerment Society, 2(2), 1-7. doi: 10.30741/eps.v2i2.457

Surbakti, R. T., \& Danil, L. (2020). Analisis Peluang dan Tantangan Industri Coworking Space Studi Kasus: Co\&Co Working Space Bandung. MANNERS, 3(1), 25-41.

Tsamara, A. N., \& Nugraha, J. (2021). Penerapan Service Excellence Sebagai Upaya Peningkatan Kualitas Layanan Humas Pemerintah Kota Surabaya (Studi Pada Koridor Co-Working Space). Jurnal Pendidikan Administrasi Perkantoran (JPAP), 9(1), 224-235.

Weijs-Perrée, M., van de Koevering, J., Appel-Meulenbroek, R., \& Arentze, T. (2019). Analysing user preferences for Co-Working Space characteristics. Building Research \& Information, 47(5), 534-548. doi: 10.1080/09613218.2018.1463750 


\section{Halaman Ini Dikosongkan}

